\title{
Factors affecting the adoption and diffusion of Internet in higher educational institutions in Kenya
}

\author{
Jimmy Macharia \& Emmanuel Nyakwende
}

\begin{abstract}
Several studies have shown that the importance of the Internet in higher education has continued to rise over the past decade. However, researchers and practitioners have shown that resistance to end-user systems by users such as students is a widespread problem. This phenomenon has created the need to better predict, explain and increase user acceptance of technology in higher education. To fulfill this need, the understanding of the factors that encourage or hinder Internet use in learning, teaching, research and university management function has become critical in modern times. As university administrators continue investing in Information \& communication Technologies (ICTs) such as the Internet, Learning management systems(LMS) such WebCT, and plagiarism and originality tools like Turnitin to improve quality and to support learning, as well as help in dealing with educational budget cuts and increased enrollment, instructors are increasingly making their teaching materials available on the Internet. However several studies have shown that the question of whether students are making full use of the Internet to justify these investments and learning materials efforts by faculty has not been fully answered. Consequently, while administrators and instructors would like to make the Internet an effective educational tool, they need to understand what their students' attitudes towards using it are.
\end{abstract}

Since the use of the Internet in higher education is still in its early stages especially in developing countries like Kenya, many issues regarding its adoption, diffusion, infusion and use have not been fully addressed. This study was therefore conducted to provide a better understanding of how ICTs particularly the Internet are adopted, diffused, infused and used in institutions of higher learning in Kenya from a student's perspective.

This paper focuses on the influence of environmental factors to the adaption and diffusion of the Internet by a selected sample of university students. The research framework is based on the Theory of Technology Acceptance Model (TAM). We use a survey conducted among university students to explore these environmental factor issues that have been neglected by previous studies. The research establishes that Competition Pressure, Government Support, ICT Vendors Support, and Perceived Socio Economic factors influence the adoption and diffusion of the Internet. These findings provide some useful insights for governments, university administrators, educators and policy makers.

Keywords: ICTs, Internet, technology acceptance, diffusion of technology. 


\section{Introduction}

Interest in the use of Internet and Internet based learning tools such as WebCT and TurnitIn has recently increased significantly. As the learning, teaching, research and management function importance of the Internet continues to rise in higher education institutions, understanding of the factors that encourage Internet use in these institutions becomes critical (Jiang, Hsu, Klein, and Lin, 2000). Further, the revolution in Information and Communication Technology (ICT), and particularly the Internet, is exerting profound effects on institutions of higher learning.

Many researchers have identified the impact of the Internet on higher education studies (Adogbji and Akporhonor, 2005). Indeed several studies have postulated that the future of universities greatly hinges on their ability to embrace and leverage the potentials of these emerging technologies at all levels of their business activities and strategies including learning, teaching, research and administration (Venkatesh and Morris, 2000). Universities that fail to do so stand to lose to others that do so. This emerging trend is particularly critical for universities in Sub-Saharan Africa, where the usage and access of ICTs is still very low. This unfortunate situation is being exploited by universities in the developed world which are now enrolling many students from the developing economies on online certificate and degree programs administered at their abroad sites. Consequently, today's university student is increasingly demanding for advanced methods of information acquisition, manipulation, and application, and show active preference for universities with greater access to Internet based resources (Adogbji and Akporhonor, 2005).

Considering projections that the Internet will have even more pervasive effects on reengineering higher education in the coming future, universities, must take a more proactive response to these technologies (Claudine, 1998). This will only be possible by having a clear understanding of factors that influence or hinder Internet adoption and diffusion by university students, faculty and management staff. Consequently, this paper is part of a major research to investigate the factors that influence or hinder the adoption, diffusion, infusion and use of Internet in institutions of higher learning in Kenya. This paper therefore aims to answer the following question:- What are the environmental factors that influence the adoption and diffusion of the Internet by university students?

\section{Literature Review}

Predicting Internet adoption, diffusion and use has been a key area of information systems research since the discipline's inception (Burton-Jones and Hubona, 2005). Consequently several previous studies have been conducted to examine Internet usage and its antecedent factors in the research literature (Aguila-Obra and PadillaMele'ndez, 2006; Mbarika, Okoli, Byrd, and Datta, 2005; Musa, 2006; Igbaria, Guimaraes, and Davis, 1995; Igbaria, Parasuraman, and Baroundi, 1996). The theoretical basis for these studies is mainly drawn from the theories including the Theory of Reasoned Action (TRA) (Fishbein and Ajzen, 1975) the Technology 
Acceptance Model (TAM) (Davis, Bagozzi, and Warshaw, 1989; Davis, 1989), Theory of Planned Behavior (TPB) (Mathieson, 1991), and Social Cognitive Theory (Compeau, Higgins, and Huff, 1999), and the IT Diffusion Process Model (Straub, 1994). These theories form the basis for constructing our research framework. Among them, the Technology Acceptance Model (TAM) (Davis, 1989) has emerged as the theory of choice.

Although many theoretical frameworks have been used to measure technology usage satisfaction, however relatively few have been used to investigate environmental variables in the higher education context. In general, the TAM theorizes that perceived usefulness (PU) influences attitudes towards technology usage (ATT) and is an important determinant of individuals'intentions to use the technology. The goal of TAM is "to provide an explanation of the determinants of computer acceptance that is in general, capable of explaining user behavior across a broad range of end-user computing technologies and user populations, while at the same time being both parsimonious and theoretically justified" (Davis, 1989; Davis, Bagozzi, and Warshaw, 1989).

Many researchers have worked on the extension of TAM model to fit different contexts (Musa, 2006; Venkatesh and Davis, 2000; Meso, Musa, and Mbarika, 2005; Mbarika, Okoli, Byrd, and Datta, 2005). We follow that line of investigation to further provide additional understanding of the role of environmental factors, name: - Competition Pressure, Government Support, ICTs Vendor Support, and Perceived Socio Economic factors as antecedents to the perceived ease of use and perceived usefulness constructs in TAM. Our study involves 203 students that used the Internet as part of their tool of learning in their degree courses in either business, management information systems (MIS), information systems and technology (IST), or computer science departments.

Prior research in information systems has investigated the TAM constructs with environmental factors (Lymperopoulos and Chaniotakis, 2005; Nguyen, 2007; Venkatesh and Davis, 2000) however, few studies, have applied it to the Internet in higher education and have directly compared and contrasted the impact of environmental constructs on PU and PEU to further understand the PU-PEU relationship in TAM.

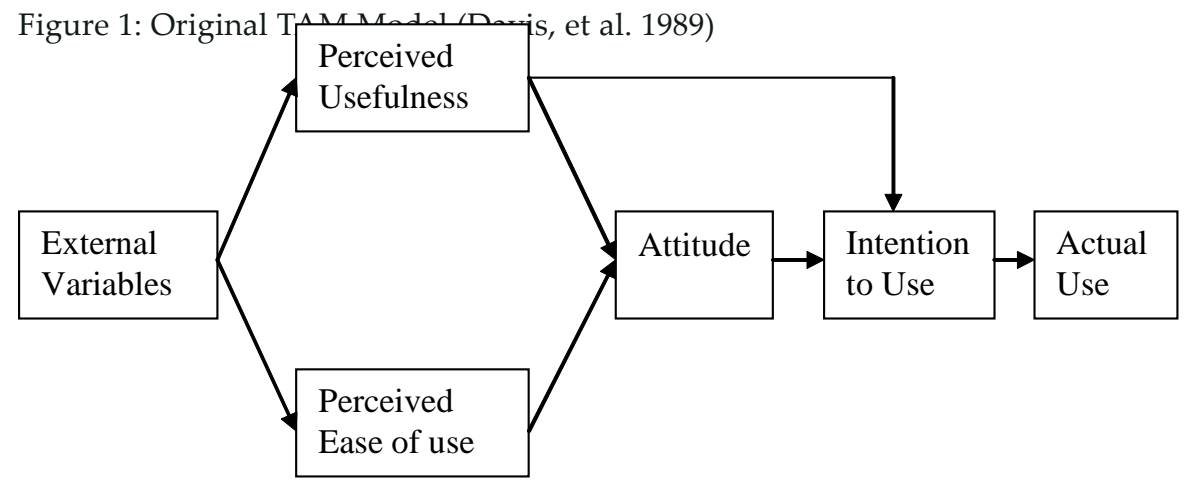


Jimmy Macharia \& Emmanuel Nyakwende 9

Figure 1 shows the original TAM. Like all theories of technology acceptance, TAM assumes that users choose to use technology based on a rational cost/ benefit tradeoff (Compeau, Higgins, and Huff, 1999) Following the Theory of Reasoned Action (TRA) (Fishbein and Ajzen, 1975), TAM maintains that the decision to use a particular technology follows four-stages: External variables" beliefs: Users consider a range of external variables (such as their individual abilities, the type of technology, the task, and situational constraints such as environmental and cultural factors) to evaluate the consequences of using a technology item. Their overall evaluation is reflected in their beliefs about a technology's usefulness (PU) (the degree to which using it will increase their job/ work or productivity performance), and ease of use (PEOU) (the degree to which using it will be free from effort and frustration); Beliefs" attitude: Users' beliefs about the consequences of using an technology (PU and PEOU) drive their attitude (or affection) toward that behavior; Attitude"intention: Users' favorable or unfavorable attitudes towards using an technology drives the extent to which they intend to use it; and Intention to use: Users' intention to use the technology drives whether they will actually use it (Ajzen and Fishbein, 1980)

\section{Theoretical Background and Research Hypothesis}

The Internet allows educators to provide learners with new and innovative virtual environments in an attempt to stimulate and enhance their learning process (Brown, 2002). In addition, Internet or web technologies are important because they support manipulation of information, facilitate/enhance communications among lecturers and students and provide tools to encourage creativity and initiative. (Saadé and Kira, 2006) posits that an impressive body of research has validated and extended TAM (Venkatesh and Davis, 2000).

An important characteristic of TAM is the degree to which each variable (beliefs, attitudes, and intention) fully mediates its antecedents (Agarwal and Prasad, 1999; Venkatesh and Davis, 2000) For example, for stages 2 and 3 (beliefs"attitudes"intention), Davis et al. (1989) argued that a key principle of TRA is that attitudes fully mediates the effects of beliefs on intentions, otherwise much of its value is foregone if it only partially mediates the impact of beliefs. Paradoxically as Figure 1's dual arrow from PU attests, Davis et al. (1989) did conclude that attitude only partially mediate PU. After other studies confirmed this effect, TAM was refined to exclude attitude because it did not fully mediate the effect of PU on usage intentions (Venkatesh, 2000). Consequently this study omitted attitude because it only partially mediates the effect of external variables.

As Figure 1 shows, TAM assumes that external variables predict usage only through their effect on PU and PEOU. Many studies have tested the effects of external variables on PEOU and PU (Dwivedi and Lal, 2007; Gribbins, 2007; Ankem, 2004; Igbaria, Guimaraes, and Davis, 1995, HIgbaria et al., 1997), or the effects of external variables independent of PEOU and PU (Compeau et al., 1999; Venkatesh et al., 2000). However only a few have tested TAM's assumption that PEOU and 
PU fully mediate the effect of external variables on intentions and behavior. Venkatesh (2000), who found that PEOU fully mediated six external variables, recognized this dearth of research, stating that his study represented an important theoretical contribution because few had tested (Venkatesh, 2000, p. 358) "the core assumption" that PEOU and PU mediated the effect of other constructs on usage intention. One such key set of external variables is users' environmental differences that are the subject of this study.

The Environmental factors Competition Intensity, Government Support, ICT Vendors Support, and Perceived Socio Economic factors have long been important in IS research (Lymperopoulos and Chaniotakis, 2005). Indeed, studies have found that environmental context is a significant factor in internet technology (Standing and Vasudavan, 2001). Despite these findings, few TAM studies have concentrated on the effects of the environmental differences. Our findings do not invalidate TAM. Rather, they uphold the importance of environmental differences as a key variable in IS (Arend, 2002; Nguyen, 2007), and they highlight that TAM's belief constructs are only partial mediators of the effects of environmental differences. Perhaps most importantly, they underline the potential for greater explanations of usage behavior when one is considering the direct effects of external variables.

TAM has proved robust and parsimonious, but it typically explains only $40 \%$ of usage intentions (Venkatesh and Davis, 2000) and 30\% of usage behavior. Consequently, many have called for increased richness in technology acceptance models (Nguyen, 2007). We believe our findings provide a way to at least partially answer this call. Figure 2 presents the research framework examined in this study, which represents an integration of the theoretical perspectives of previous studies discussed above

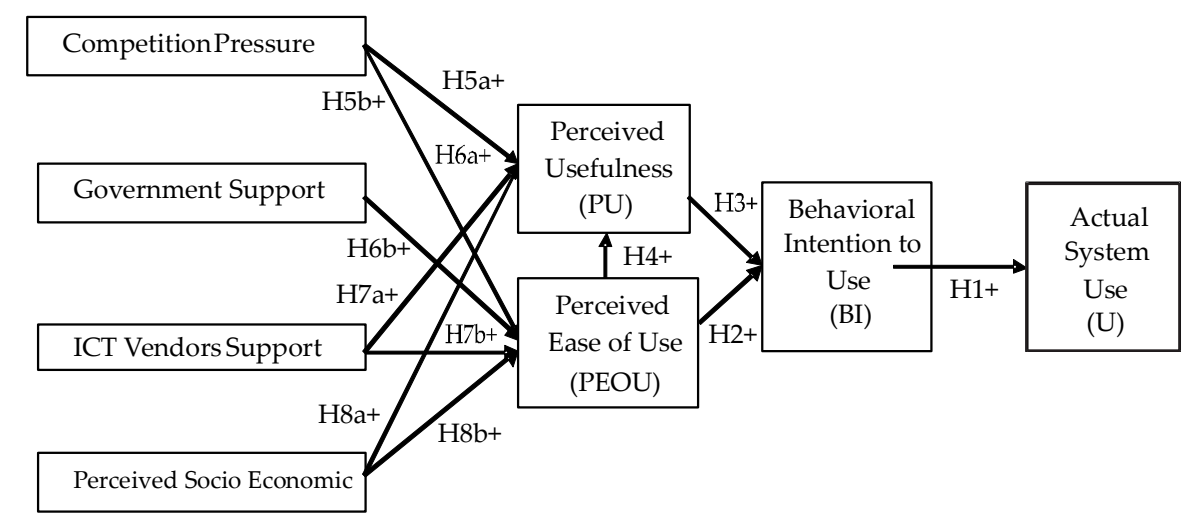

Figure 2: A research framework 
Jimmy Macharia \& Emmanuel Nyakwende

\subsection{Environmental factors}

In the area of information systems, numerous studies have found a positive correlation between environmental factors brought about by competition pressure on one hand, and IS management, and organizational performance on the other (Lee, Lin, and Pai, 2005). Grover, (1993) on the other hand, proposes that environmental, (and organizational, policy, support and system-related) factors are the ones that determine the adoption of inter-organizational information systems. Moreover, diversity in changes in competitors' strategies are positively associated with higher dependence on planning practices (Nguyen, 2007). Choe, (2003) also empirically showed a positive relationship between perceived environmental factors and IS alignment.

Furthermore, Kwon and Zmud, (1987) and Robertson and Gatignon, (1986) have developed more comprehensive frameworks for studying organizational adoption and diffusion. The Kwon and Zmud framework defines environmental factors among the five contextual factors that include user community characteristics, organizational characteristics, technology characteristics, and task characteristics. Each of these may impact any of six stages of ICT implementation (initiation, adoption, adaptation, acceptance, routinization, and infusion.

It should be borne in mind that there are macro-environmental factors common to all institutions, such as changes in the political climate and product market competition, which may influence technology adoption which we cannot account for in our micro-analysis at institutional-level (Lee, Lin, and Pai, 2005). Further research has suggested that social and environmental factors may indeed have great significance in ICT diffusion. Consumer behavior studies have found for example, that when countries converge in respect to national income, cultural and environmental variables help to explain differences in country-level consumer behavior (de Mooij and Hofstede, 2002). Research has found that developing countries lag in adopting modern technologies for various reasons, among which are geo-political, cultural, structural, ethnic, environmental and socio-economic policy factors (Meso, Musa, and Mbarika, 2005).

\subsection{Competition Intensity}

Robertson and Gatignon, (1986) proposed that a variety of competitive effects in the technology consumer's industry (competitive intensity, demand uncertainty, professionalism, cosmopolitanism) and within the technology supplier's industry (level of competitiveness, reputation, $\mathrm{R}$ and $\mathrm{D}$ allocation, technology standardization) impact the rate and level of diffusion. The Kwon and Zmud framework is most relevant to studying differences in adopter innovativeness, while Robertson and Gatignon are more concerned with variables affecting the macro diffusion process. Institutions facing environmental uncertainty due to stiff competition thus have a greater incentive to enhance the alignment of information systems and business strategies and improve their organizational planning capabilities (Lee, Lin, and Pai, 2005). The following hypotheses for these factors are thus formulated: 
12 Jimmy Macharia \& Emmanuel Nyakwende

H5a. Competition Pressure positively affects the Internet adoption and diffusion .

H5b. Competition Pressure positively affects the Internet adoption and diffusion

\subsection{Government support}

Technology and know-how are diffused through various channels and involve a broad range of private and public actors which together make up national innovation systems (OECD, 1997). The rationale for government support to technology diffusion rests on arguments of market and systemic failure. OECD argues that governments also support technology diffusion to increase returns from public investments in $R \& D$ and to enhance industrial competitiveness. Government technology diffusion initiatives in OECD countries have evolved from programmes to transfer specific technology embodied in equipment and related know-how to enhancing the ability of firms, especially small and medium-sized enterprises, to absorb technology and improve performance (OECD, 1997).

The underlying cause for the physical infrastructure divide is rather complex and beyond the scope of this paper. It is mediated by historical and global governance factors but, more importantly, by local poverty and injustice and the extent to which public policies provide incentives to the diffusion of Internet and supportive infrastructure. Previous studies have shown that this phenomenon is particularly serious for Sub-Saharan African countries including Kenya (Mbarika, Okoli, Byrd, and Datta, 2005). The following hypotheses are thus formulated for this variable:

H6a. Government Support positively affects the Internet adoption and diffusion .

H6b. Government Support positively affects the Internet adoption and diffusion.

\subsection{ICT Vendors Support}

There is some evidence to support the idea that ICT vendor support is associated with Behavioural intention to use Internet (Kim and Galliers, 2004). Other researchers have found that ICT take-up amongst SMEs varies by sector, and this variation depends on the degree to which an industry (often internationally) has developed in terms of ICT use (Hawkins and Prencipe, 2000; Smallbone and North, 1999; Daniel, 2003). The Government National ICT policy formulation and support is fundamental in order to utilize ICT to its full potential. There is scarcity of ICT policies in the African continent (Mbarika, Okoli, Byrd, and Datta, 2005). Jain, (2006), and Kalusopa, (2005) have identified ICT vendors support as one of the External factors related to ICT adoption and diffusion, while the rest include network performance, compatibility, relative advantage, costs, telecommunication infrastructure, marketing efforts by ICT vendors, technology innovation and availability of Internet payment applications. The following hypotheses thus are formulated for this variable: 
Jimmy Macharia \& Emmanuel Nyakwende 13

H7a. ICT Vendors Support positively affects the Internet adoption and diffusion.

H7b. ICT Vendors Support positively affects the Internet adoption and diffusion .

\subsection{Perception of Socio-Economic Support}

The (Miller, Esselaar and Associates, 2002) study assessed the impact of the policy and socio-economic frameworks on the diffusion, utilization and benefits of ICTs by using benchmarking methods. The study found that Internet use is closely related to a household's socio-economic status. For example, according to statistics Canada, the highest proportion of regular Internet users in 1998 was found in households with revenues in the top quartile $(65 \%)$ and in which the head of the household had a university degree. South Africa ranks in the top twenty countries for the use of the Internet, and represents more than $90 \%$ of the Internet users and unique Internet hosts on the Continent of Africa.

The number of individual dial-up connections is estimated to be approximately 400,000 (Miller, Esselaar and Associates, 2002). Studies by Dwivedi and Lal, (2007), and Arend, (2002), have shown that (Dwivedi \& Lal, 2007; Arend, 2002)both PC and Internet adoption indicates that socio-economic factors (such as income, level of education, and marital status) and demographic factors (such as age, sex and race/ ethnicity) continue to be the variables most correlated with IT home adoption. Researchers have shown that the interactions between socio-economic development needs and factors generally are innate to sub-Sahara Africa and other developing countries, and that they impede sustainable technological adoption and diffusion (Musa, Meso, and Mbarika, 2005). Most reports on disparities in ICT access within countries look at the problem according to socio-economic criteria.

The study by (Yang and Lee, 2003) identified the following socio-economic factors: Race, Income, Geographical location, Education, Age, Gender and Disparity. The following hypotheses thus are formulated:

H8a. Socio-economic factors positively affects the Internet adoption and diffusion.

H81b. Socio-economic factors positively affects the Internet adoption and diffusion.

\section{Research methodology}

A research questionnaire was randomly distributed to 400 undergraduate students across different schools and departments in three different universities. A response rate of $2003,50 \%$ was obtained completed and returned $59 \%$ were male and $41 \%$ were female. The survey questionnaire was adapted from the validated constructs of previous relevant studies. Students were asked to indicate the extent of their agreement or disagreement with the statements on the questionnaire on a sevenpoint scale ranging from 1 (Very strongly disagree) to 7 (Very strongly agree).

The variables to measure personal perceptions and attitudes were directly derived from the TAM. These were: perceived usefulness (PU). Perceived ease of use (PEOU, behavioral intention (BIU) an usage. Each variable had a number of constructs 
14 Jimmy Macharia \& Emmanuel Nyakwende

derived from previous studies. For example in the case of $U$ which assesses the benefits of Internet use for university study, examples of the statements are: 'Use of the Internet/www can increase the effectiveness of my study performance' and 'Taking into account all tasks, the use of the Internet/www helps improve my learning/study'.

Behavioral intention to use the Internet is commonly assessed using two criteria: intention to use for learning and study, and intention to use for social activities (Igbaria, Parasuraman, and Baroundi, 1996, Igbaria Guimaraes, and Davis, 1995). Two statements were used to measure this construct (eg. Igbaria et al, 1995): 'I intend to use the internet/www for my learning and studies' and 'I intend to use the internet/ www, for social activities and general information'. The mean of the two items was used as the index of behavioral intention to use the Internet.

Some demographic information, such as gender, age, study year and current study program, was also captured using single item questions. Objective logs of Internet use were not available in this research because the student subjects were spread across different departments and universities, and different computer systems are used for different tasks. In this scenario, Blair and Burton, (1987) posts that selfreported measures are considered suitable for research purposes.

\section{Data Analysis}

The results of descriptive statistics are shown in Table 1. A greater mean value in Table 1 generally indicates a higher level of measured construct. Since this study is exploratory in nature, the collected data are further analyzed using the Bivariate Correlation test. The Bivariate Correlation test computes Pearson's correlation coefficient, and measures how variables or rank orders are related. Pearson's correlation coefficient is a measure of linear association.

Table 1: Descriptive Statistics

\begin{tabular}{|l|l|l|l|l|l|}
\hline & $\mathrm{N}$ & Minimum & Maximum & Mean & $\begin{array}{c}\text { Std. } \\
\text { Deviation }\end{array}$ \\
\hline Competition Intensity & 186 & 1.60 & 7.00 & 5.0398 & 1.10699 \\
\hline Government Support & 195 & 1.00 & 7.00 & 4.8137 & 1.39998 \\
\hline ICT Vendors Support & 197 & 1.33 & 7.00 & 5.8596 & 1.35652 \\
\hline Perceived Socio Economic & 195 & 1.00 & 7.00 & 5.2038 & 1.21727 \\
\hline PU-Perceived Usefulness & 186 & 1.00 & 7.00 & 6.0901 & 1.30110 \\
\hline PEOU-Perceived Ease of Use & 195 & 1.00 & 7.00 & 5.2038 & 1.21727 \\
\hline Behavioral Intension To Use & 186 & 2.50 & 7.00 & 5.8360 & 1.13602 \\
\hline Valid N (listwise) & 105 & & & & \\
\hline
\end{tabular}


The results of reliability tests for all the constructs used in the survey questionnaire for this paper are reported in Table 2 . These constructs were factor analyzed to validate this reliability for the measurements in this study. It can be observed in Table 2 that the Cronbach's alpha values for all constructs except perceived socio-economic factors are larger than 0.70 , indicating good construct reliability according to Nunnally, (1978). The perceived socio-economic factors constructs have alpha values of less than 0.70 , indicating relatively less satisfactory construct reliability. Since these constructs have been proposed in the current study, it should be a subject requiring further address in future research.

Table 2: Cronbach's alpha values of all constructs

\begin{tabular}{|l|c|c|c|}
\hline Environmental Context & $\begin{array}{l}\text { Cronbach's } \\
\text { Alpha }\end{array}$ & $\begin{array}{l}\text { Cronbach's Alpha } \\
\text { Based on } \\
\text { Standardized Items }\end{array}$ & $\begin{array}{l}\text { N of Construct } \\
\text { Items }\end{array}$ \\
\hline$\bullet$ Competition Intensity & .721 & .647 & 5 \\
\hline$\bullet$ Government Support & .794 & .795 & 3 \\
\hline$\bullet$ ICT Vendors Support & .868 & .870 & 4 \\
\hline$\bullet$ Perceived Socio Economic & 548 & .554 & 4 \\
\hline$\bullet$ PU-Perceived Usefulness & .951 & .951 & 2 \\
\hline$\bullet$ PEOU-Perceived Ease of Use & .886 & .888 & 4 \\
\hline$\bullet$ Behavioral Intension To Use & .766 & .769 & 2 \\
\hline
\end{tabular}


16 Jimmy Macharia \& Emmanuel Nyakwende

Table 3 presents the results of the Bivariate Correlation tests and the discussion of the results follows below.

Table 3: Bivariate Correlation analysis : Pearson Correlations

\begin{tabular}{|c|c|c|c|c|c|c|c|}
\hline & $\begin{array}{c}\text { Competition } \\
\text { Pressure }\end{array}$ & $\begin{array}{c}\text { Government } \\
\text { Support }\end{array}$ & $\begin{array}{l}\text { ICT Vendor } \\
\text { support }\end{array}$ & $\begin{array}{l}\text { Perceived } \\
\text { Socio- } \\
\text { economic }\end{array}$ & PU & PEOU & BIU \\
\hline Competition Pressure & 1 & & & & & & \\
\hline Government Support & $.2811^{(* *)}$ & 1 & & & & & \\
\hline ICT Vendor support & $.218\left(^{(* *)}\right.$ & $.319^{(*)}$ & 1 & & & & \\
\hline Perceived Socio-economic & $.303(* *)$ & $\left..360{ }^{(* *}\right)$ & $.444\left(^{* *}\right)$ & 1 & & & \\
\hline PU & $.209^{(* *)}$ & $.180\left(^{*}\right)$ & $.262(* *)$ & $.342(* *)$ & 1 & & \\
\hline PEOU & .137 & $.154\left(^{*}\right)$ & .114 & $.236\left(^{(* *}\right)$ & $\left..411^{(* *}\right)$ & 1 & \\
\hline BIU & $.228\left(^{(* *)}\right.$ & $\left..3311^{* *}\right)$ & $.321\left({ }^{* *}\right)$ & $.283\left({ }^{* *}\right)$ & $.346\left(^{(* *}\right)$ & $.303(* *)$ & 1 \\
\hline $\mathrm{N}$ & 172 & 182 & 182 & 180 & 177 & 183 & 186 \\
\hline
\end{tabular}

** Correlation is significant at the 0.01 level (2-tailed).

* Correlation is significant at the 0.05 level (2-tailed).

\section{Discussion and Implications}

It is observed in Figure 2 and Table 3 that the environmental factors of Competition pressure, Government Support, ICT Vendors Support and Perceived Socio Economic factors are positively correlated with Perceived Usefulness (PU). Except for competition pressure, all the other three factors had a significant correlation with PU and Perceived Ease of Use (PEOU). In addition, the environmental factors were significantly associated with behavioural Intention to use the Internet.

There are various types of possible support that may be provided at the environmental context level by government and ICT vendors like the Internet Service Providers (ISPs), such as tax incentives for ICTs and premium rates for internet bandwidth for higher educational institutions. Our current research findings suggest that providing these types of support may lead to greater Internet use and more effective learning by students. Effective government support requires both the necessary policies and laws to provide adequate ICTs facilities for students to access the Internet, and a supportive macro environment or culture that encourages Internet use as part of higher education. 
The two variables Perceived Usefulness and Perceived Ease of Use were found to correlate positively with Behavioural intention to Use the Internet. Perceived usefulness had the highest correlation with BIU. Therefore, to promote greater Internet usage in higher education, universities can make use of motivating mechanisms such as extrinsic motivators. In this way, highly motivated students may increase their usage of the Internet, and also, create a critical mass of users who will intern put peer pressure to other students, and thus increase Internet adoption and diffusion in the universities.

\section{Research limitations}

We can identify a few research limitations to this research. First, some level of 'Hawthorne effect' discussed for example in (Adair, 1984) may have existed because the survey measured students' perceptions and attitudes (Cheung and Huang, 2005). Second, most students in this survey were undergraduate students who may not have had a great exposure to ICTs or a clear understanding of macro or environmental factors pertaining to the support of the Internet sector. Consequently, the research results concerning the relationship between Behavioural intention to use the Internet and environmental factors may not fully reflect the views of senior and graduate students. Third, all statements in the survey questionnaire were largely worded in one direction, rather than two directions. Future work should take these study limitations into consideration at the design stage, so that research can be enhanced and hence attain better accuracy.

\section{Conclusions}

In summary, some relationships between the environmental factors specified in the research framework of Figure 2 were supported. Behavioural intention to use Internet was found to correlate significantly with environmental context factors - competition pressure, government support and ICT vendor's support, and perceived socioeconomic factors. The perception factors, Perceived Usefulness (PU) were significantly correlated to Behavioral Intension To Use (BIU) the internet. As a result, according to the research model in Figure 2, Internet usage which is directly influenced by BIU will be associated with environmental factors.

The results provide some justification for university investment in Internet technology to promote adoption and diffusion of ICTs and hence promote Internet use in higher education. Some of the antecedents of Internet use that are found in this research may help universities to lobby and advocate for government support of tax regime that favours higher education sector, and provision of premium priced Internet bandwidth for universities. Governments and policy makers need to better allocate their limited financial and human resources, and establish better policies to achieve the goal of promoting greater Internet use in higher education.

Based on the research findings and research model, some suggestions for specific measures that could be implemented by governments, ICT sector vendors and universities to effectively increase Internet use and enhance students' learning performance are as follows: 
18 Jimmy Macharia \& Emmanuel Nyakwende

(1) Governments should provide higher education with tax incentives in the acquisition of hardware and software for educational purposes. These will encourage universities to increase ICTs access for Internet usage,

(2) Government in collaboration with ICT vendors such as ISPs and Telecommunication companies should also have special bandwidth access rates for higher education, and

(3) Universities should lobby and advocate for Internet support from both government and ICT vendors.

All of these elements may encourage positive beliefs and attitudes in students, which in turn could result in more Internet use to support their learning and study. The greatest motivator (PU) can be used to promote Internet use in university study. This means that Telecommunication companies and ICT vendors such as Internet service providers or Internet software designers should consider providing functions more suited to higher education study as part of their Internet software packages and services, as well as developing more interesting and user-friendly software interfaces. This motivator could increase the use of Internet technology in university education.

This exploratory study identifies some important antecedent factors that may enhance Internet use, as well as having a positive impact on university learning. While Internet use in university education is becoming more widespread and provides a supplement to traditional teaching methods, more extensive research in this area should be conducted to fully understand what factors lead to greater Internet use and better learning performance in students.

\section{References}

Adair, J. G. (1984). The Hawthorne Effect-a reconsideration of the methodological artifact. Journal of Applied Psychology , 69 (2), 334-345.

Adogbji, B., \& Akporhonor, A. B. (2005). The impact of ICTs (internet) on research and studies; The experience of Delta state university students in Abraka NIGERIA. Library HiTech News , 1 (10), 17-21.

Agarwal, R., \& Prasad, J. (1999). Are Individual Differences Germane to the Acceptance of New Information Technologies? Decision Sciences , 30 (2), 361391.

Aguila-Obra, A. R., \& Padilla-Mele'ndez, A. (2006). Organizational factors affecting Internet technology adoption. Internet Research , 16 (1), 94-110.

Ajzen, I., \& Fishbein, M. (1980). Understanding Attitudes and Predicting Social Behavior. Englewood Cliffs, New Jersey: Pretice-Hall.Retrived Jan 24,2007 from,http:// 
www.amazon.com/Understanding-Attitudes-Predicting-Social-Behavior/ dp/0139364358.

Ankem, K. (2004). Adoption of Internet resource-based value-added processes by faculty in LIS education. Library and Information Science Research, 26 (4), $482-500$.

Arend, M. (2002). Socio-economic analysis and macro-modelling of adapting to information technology in europe. Zürich: Econcept (Switzerland).

Blair, E., \& Burton, S. (1987). Cognitive Processes Used by Survey Respondents to Answer Behavioral Frequency Questions. Journal of Consumer Research, , 14, 280-288.

Burton-Jones, A., \& Hubona, G. S. (2005). Individual Differences and Usage Behavior: Revisiting a Technology Acceptance Model Assumption. . The Data Base for Advances in Information Systems , 36 (2), 58-77.

Cheung, W., \& Huang, W. (2005). Proposing a framework to assess Internet usage in university education: an empirical investigation from a student's perspective. British Journal of Educational Technology , 36 (2), 237-253.

Choe, J. (2003). The effect of environmental uncertainty and strategic applications of IS on firms' performance. Information and Management , 40 (4), 257-68.

Claudine, L. (1998). Universities and new information and communication technologies: issues and strategies. European Journal of Engineering Education, 23 (3), 285-96.

Compeau, D. R., Higgins, C. A., \& Huff, S. (1999). Social cognitive theory and individual reactions to computing technology: A longitudinal study. MIS Quarterly , 23 (2), 145-158.

Daniel, E. (2003). An exploration of the inside-out model: e-commerce integration in UK SMEs. Journal of Small Business and Enterprise Development , 10 (3), 233-49.

Davis, F. D. (1989). Perceived Usefulness, Perceived Ease of Use, and User Acceptance of Information Technology. MIS Quarterly, 13 (3), 318-339.

Davis, F. D., Bagozzi, R. P., \& Warshaw, P. R. (1989). User acceptance of computer technology: A comparison of two theoretical models. Management Science, 35, 982-1003.

de Mooij, M., \& Hofstede, G. (2002). Convergence and divergence in Consumer Behavior; Implications for International Retailing. , Journal of Retailing , 78 (1), 61-69. 
20 Jimmy Macharia \& Emmanuel Nyakwende

Dwivedi, Y. K., \& Lal, B. (2007). Socio-economic determinants of broadband adoption. Industrial Management \& Data Systems , 107 (5), 654-671.

Fishbein, M., \& Ajzen, I. (1975). Belief, Attitude, Intention and Behavior: An Introduction to Theory and Research. Addison-Wesley. Reading MA, 1975.Retrived September 23,2007from,http://scholar.google.com/scholar?q = Belief, + Attitude, + Intention + and + Behavior: + An + Introduction + to + Theory + and + Research\&hl $=$ en\&um $=1 \&$ ie $=$ UTF-8\&oi $=$ scholart.

Gribbins, M. (2007). The Perceived Usefulness of Podcasting in Higher Education. Proceedings of the Second Midwest United States Association for Information Systems (pp. 18-19). Springfield: University of Illinois at Springfield.

Grover, V. ( 1993). An empirically derived model for adoption of customer-based interorganisational systems. Decision Sciences , 24 (3), 603-640.

Hawkins, R., \& Prencipe, A. (2000). Business to Business E-commerce in the UK: A Synthesis of Sector Reports, commissioned by the Department of Trade and Industry, London. Retrived May 17, 2008 from,http:// $\mathrm{www}$. emeraldinsight.com/ Insight/view ContentItem.do; jsessionid = 5B68D60333B73E6D35DE349B28D4CD06 contentType = Article\&hdAction $=\operatorname{lnkhtml\& contentId}=1636472 \&$ dType $=$ SUB\&history $=$ false.

Igbaria, M., Guimaraes, T., \& Davis, G. (1995). Testing the Determinants of Microcomputer Usage via a Structural Equation Model. Journal of Management Information Systems, 11 (4), 87-114.

Igbaria, M., Parasuraman, S., \& Baroundi, J. J. (1996). A Motivational Model of Microcomputer Usage. Journal of Management Information Systems , 13 (1), 127143.

Jain, P. (2006). Empowering Africa's development using ICT in a knowledge management approach. The Electronic Library , 24 (1), 51-67.

Jiang, J. J., Hsu, M. K., Klein, G., \& Lin, B. (2000). E-commerce user behavior model:an empirical study. Human Systems Management, 19 (1), 265-276.

Kalusopa, T. (2005). The challenges of utilizing information communication technologies (ICTs) for the small scale-farmers in Zambia. Library Hi Tech , 23 (3), 414-424.

Kim, C., \& Galliers, R. D. (2004). Deriving a Diffusion Framework and Research Agenda for Web-based Shopping Systems. Journal of Electronic Commerce Research , 5 (3), 199-215. 
Jimmy Macharia \& Emmanuel Nyakwende 21

Kwon, T., \& Zmud, R. (1987). Unifying the Fragmented Models of Information SystemsImplementation, in Critical Issues in Information Systems Research. (e. R. Hirshheim, Ed.) NY: John Wiley \& Sons,.

Lee, G.-G., Lin, H.-F., \& Pai, J.-C. (2005). Influence of environmental and organizational factors on the success of internet-based interorganizational systems planning. Internet Research , 15 (5), 527-543.

Lymperopoulos, C., \& Chaniotakis, I. E. (2005). Factors affecting acceptance the internet as marketing-intelligence among employees of branches. International Journal of Bank Marketing , 23 (6), 484-505.

Mathieson, K. (1991). Predicting User Intentions: Comparing the Technology Acceptance Model with the Theory of Planned Behavior. Information Systems Research , 2 (3), 173-191.

Mbarika, V. W., Okoli, C., Byrd, T. A., \& Datta, P. (2005). The Neglected Continent of IS Research: A Research Agenda for Sub-Saharan Africa. Journal of the Association for Information Systems , 6 (5), 130-170.

Meso, P., Musa, P., \& Mbarika, V. (2005). Towards a model of consumer use of mobile information and communication technology in LDCs: the case of sub-Saharan Africa. Info Systems J , 15, 119-146.

Miller, Esselaar \& Associates. (2002). ICT Diffusion and ICT Applications in Usage Sectors. Retrieved from http://www.savant.co.za/Portals/0/docs/Published\%20$\% 20 I C T \% 20$ Diffusion\%20-\%20Executive\%20Summary.pdf. South African IT Industry Strategy (SAITIS) Project(SAITIS).

Musa, P. F. (2006). Making a Case for Modifying the Technology Acceptance Model to Account for Limited Accessibility in Developing Countries. Information Technology for Development, 12 (3), 213-224.

Musa, P. F., Meso, P., \& Mbarika, V. W. (2005). Toward sustainable adoption of technologies for human development in sub-saharan africa: precursors, diagnostics, and prescriptions. Communication of the Association of Information Systems , 15 (33), 1-31.

Nguyen, T. D. (2007). Factors affecting the utilization of the internet by internationalizing firms in transition markets. Marketing Intelligence E Planning , 25 (4), 360-376.

Nunnally, J. C. (1978). Psychometric theory (2nd ed. ed.). New York: McGraw-Hill.

Robertson, T. S., \& Gatignon, H. (1986). Competitive Effects on Technology Diffusion. Journal of Marketing , 50, 1-12. 
22 Jimmy Macharia \& Emmanuel Nyakwende

Smallbone, D., \& North, D. (1999). Innovation and new technology in rural small and medium-sized enterprises: some policy issues. Environment and Planning C: Government and Policy , 17 (1), 549-66.

Standing, C., \& Vasudavan, T. (2001). Diffusion of Internet Technologies in Travel Agencies in Australia. Retrived Jan 202007 from http://scholar.google.com/ scholar?q = Diffusion + of +Internet + Technologies + in+ Travel + Agencies + in + Australia\&hl $=$ en\&um $=1 \& i e=U T F-8 \& o i=$ scholart.

Straub, D. W. (1994). The effect of culture on IT diffusion: E-mail and FAX in Japan and the U.S. Information Systems Research , 5, 23-47.

Venkatesh, V. (2000). Determinants of Perceived Ease of Use: Integrating Control, Intrinsic Motivation, and Emotion into the Technology Acceptance Model. Information Systems Research, 11 (4), 342-365.

Venkatesh, V., \& Davis, F. (2000). A Theoretical Extension of the Technology Acceptance Model: Four Longitudinal Field Studies. Management Science , 46 (2), 186-204.

Venkatesh, V., \& Morris, M. G. (2000). Why don't men ever stop to ask for directions? Gender, social influence, and their role in technology acceptance and usage behavior. MIS Quarterly, 24 (1), 115-139.

Yang, K. H., \& Lee, S. G. (2003). Comparison of the ICT Adoption Pattern: In the Case of Korea and the U.S. La Crosse: Department of Management Information Systems, School of Business Administration, University of Wisconsin. 